\title{
Umpolung of Indoles: Triflic Acid-Mediated C3-Regioselective Hy- droarylation of N-H Indoles
}

\author{
Nazarii Sabat,,${ }^{1,2, \$}$ Weiping Zhou, ${ }^{1,2, \$}$ Vincent Gandon, ${ }^{1,3 *}$ Xavier Guinchard, ${ }^{2 *}$ Guillaume Vincent ${ }^{1 *}$ \\ †These authors contributed equally.
}

\begin{abstract}
${ }^{1}$ Institut de Chimie Moléculaire et des Matériaux d’Orsay (ICMMO), Université Paris-Saclay, CNRS, 91405, Orsay, France
${ }^{2}$ Université Paris-Saclay, CNRS, Institut de Chimie des Substances Naturelles, UPR 2301, 91198, Gif-sur-Yvette, France

${ }^{3}$ Laboratoire de Chimie Moléculaire (LCM), CNRS UMR 9168, Ecole Polytechnique, Institut Polytechnique de Paris,
\end{abstract}

France

vincent.gandon@universite-paris-saclay.fr

xavier.guinchard@cnrs.fr

guillaume.vincent@universite-paris-saclay.fr

The direct dearomative addition of arenes to the C3-position of unprotected indoles is reported under operationally simple conditions, using triflic acid at room temperature. The present regioselective hydroarylation is a straightforward manner to generate an electrophilic indole at the C3-position without the need of a deactivating acetyl group at the indolic nitrogen as in previously reported strategies. This atom economical method delivers biologically relevant 3-arylindolines and 3,3-spiroindolines in high yields and regioselectivities from both intra- and intermolecular processes. DFT computations suggest the stabilization of cationic or dicationic intermediates with $\mathrm{H}$-bonded (TfOH) ${ }_{n}$ clusters.

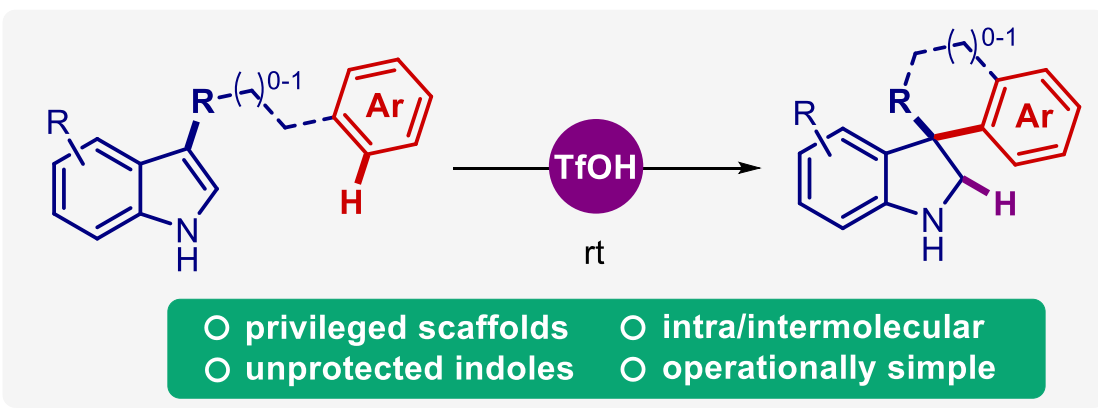

The indole nucleus displays a strong nucleophilicity at the C3-position, ${ }^{1}$ allowing reactions with a range of electrophiles. In this context, addition of nucleophiles at the $\mathrm{C} 2$-position of $\mathrm{N}-\mathrm{H}$ indoles $\mathbf{1}$ is possible under acidic conditions after protonation of the $\mathrm{C} 3$ position $\left(\mathrm{E}=\mathrm{H}\right.$ ), leading to products $\mathbf{3}$ via the iminium species $\mathbf{2}$ (Scheme 1a). ${ }^{3}$ This typical reactivity pattern has been widely exploited in dearomatization strategies. ${ }^{2}$ However, in presence of an acid, dimerization of N-H indoles $\mathbf{1}$ into dimers $\mathbf{4}$ is often observed after $\mathrm{C} 2$-addition of one indole to the iminium intermediate $\mathbf{2} .^{3 \mathrm{a}, \mathrm{c}}$ The formation of compounds $\mathbf{5}$, featuring a 6-membered ring,

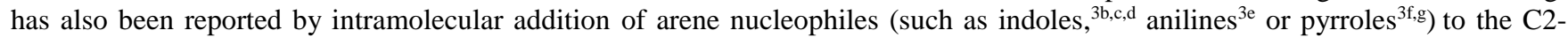
iminium intermediate. The intermolecular addition of a nucleophile ${ }^{3 \mathrm{~h}, \mathrm{i}, \mathrm{k}, \mathrm{m}}$ has been more rarely achieved since it requires a more reactive species than the indole itself to prevent dimerization into $4 .^{3 \mathrm{a}}$ For instance, the addition of 1,3 -dimethoxybenzene at the $\mathrm{C} 2$ position of tryptamine derivatives into $\mathbf{6}$ was described by Laronze in trifluoroacetic acid. ${ }^{3 \mathrm{~h}}$ However, the regioselective nucleophilic addition to the $\mathrm{C} 3$-position of $\mathbf{1}$ to give $\mathbf{8}$ (via electrophilic intermediate 7) appears to be mechanistically less favorable since it involves the reversal of the inherent reactivity of the indole ring (Scheme 1b).

Over the past decade, we have been interested in the Umpolung of indoles and we aimed at developing synthetic dearomatization methods that overturn this innate reactivity of the indole nucleus. ${ }^{4,5}$ Based on preliminary findings from the group of Nakatsuka, ${ }^{6}$ we reported the intermolecular regioselective C3-hydroarylation of 3-substituted $N$-Ac indole derivatives 9 by electron-rich arenes $\mathbf{1 0}$ in presence of typically more than 2 equivalents of $\mathrm{FeCl}_{3}$, or TfOH (Scheme 1c). ${ }^{7-9} 10,11{ }^{12}$ However, the regioselectivity of the intramolecular version of this reaction depends on the length of the tether between the indole and the arene nucleophile: a three carbon linker 
leads to 3,3-spirocyclic indolines 13 via the formation of a 6-membered ring, ${ }^{8,12}$ while a two carbon linker favors the formation of 6membered ring-fused indolines $\mathbf{1 4}$ by addition of the arene at the C2-position. Nevertheless, this expedient access to biologically relevant spiroindolines ${ }^{13}$ contrasts with the classical dearomatizing methods ${ }^{2}$ relying on the typical indole nucleophilicity, including our own recent efforts using $\mathrm{Au}(\mathrm{I})$ catalysis. ${ }^{14}$ Beyond these regioselectivity issues, the reaction requires the substitution of the indolic nitrogen by an acetyl group, which has to be incorporated upstream and which removal usually necessitates rather strong conditions (aq. $\mathrm{HCl}, \mathrm{EtOH}, 85^{\circ} \mathrm{C}$ ).

Aiming to simplify and generalize our synthetic method, we finally found that unprotected indoles $\mathbf{1}$ undergo intra- or intermolecular hydroarylations mediated by $\mathrm{TfOH}$ (Scheme 1e). In this paper, we report the development of a rare redox-neutral C3-regioselective dearomative arylation ${ }^{9}$ of $\mathrm{NH}$-indoles $\mathbf{1}$ for the synthesis of 3-arylindolines and 3,3-spiroindolines $\mathbf{1 5}$ and provide a mechanistic rationale supported by DFT calculations.

Scheme 1. Hydroarylation of electrophilic indoles
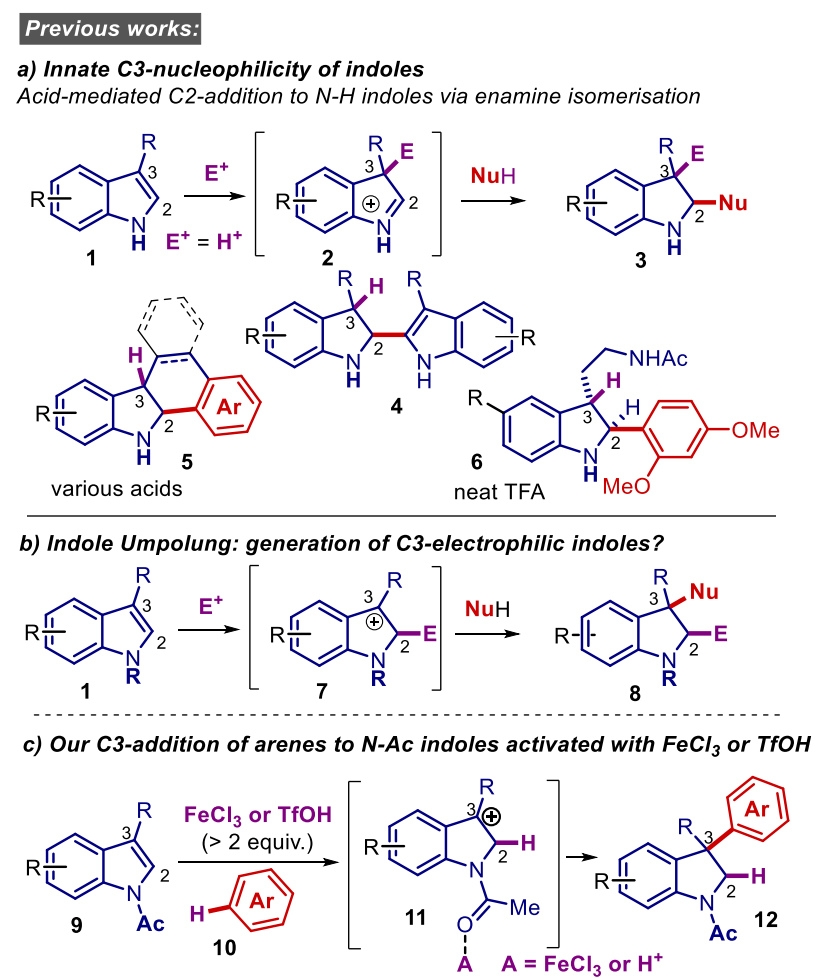

d) Tether-length-dependant regioselectivity of the intramolecular version

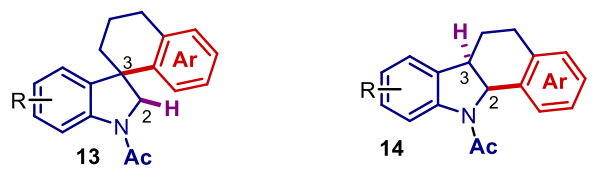

This work:

e) TfOH-mediated C3-addition without a deactivating N-Ac group

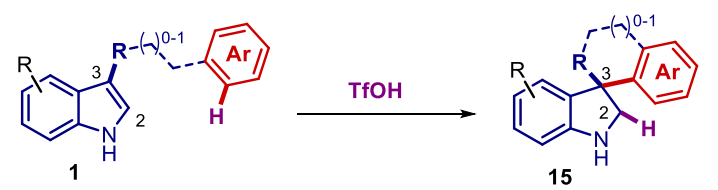

We started our study by optimizing the dearomative cyclization of N-H indole 1a, which contains a nucleophilic para-tolyl moiety (Table 1). Under strong acidic conditions and without an acetyl deactivating group, we envisioned that this reaction might lead to the desired spiroindoline 15a, but we were most likely expecting the formation of the seven-membered ring compound 16a and the dimer product 4a. ${ }^{3 \mathrm{a}-\mathrm{g}}$ Indeed, treating $\mathbf{1 a}$ with 1.0 or 1.5 equivalents of TfOH mainly led to dimer $\mathbf{4 a}$ (entries 1,2 ). Strikingly, increasing the amount of $\mathrm{TfOH}$ to 2.5 equivalents led exclusively to the formation of the 3,3-spiroindoline 15a without any traces of 16a or $\mathbf{4 a}$ (entry 3).

This finding led us to the conclusion that the $N$-Ac deactivating group is not mandatory to orientate the hydroarylation towards the C3-position. This discovery represents a major practical and conceptual advance: in addition to avoid the undesirable introduction and removal of a functional group, it also demonstrates that the delocalization of the nitrogen lone pair into an electron-withdrawing group is not essential to generate the $\mathrm{C} 3$-electrophilicity of the indole nucleus. 
Table 1. Optimization of the intramolecular hydroarylation of indole $1 \mathrm{a} .{ }^{\mathrm{a}}$

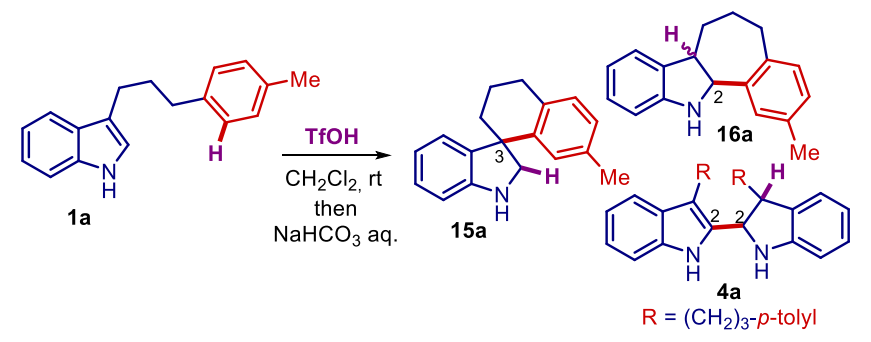

\begin{tabular}{ccccc}
\hline Entry & Equiv. TfOH & \multicolumn{3}{c}{ NMR yield $^{\mathrm{b}}$} \\
& & $\mathbf{1 5 a}$ & $\mathbf{1 6 a}$ & $\mathbf{4 a}$ \\
\hline 1 & 1.0 & $0 \%$ & $0 \%$ & $80 \%$ \\
2 & 1.5 & $2 \%$ & $0 \%$ & $54 \%$ \\
3 & 2.5 & $99 \%$ & $0 \%$ & $0 \%$ \\
\hline
\end{tabular}

a Reactions conditions: 0.05 mmol of 1 a and $x$ equiv. of TfOH in $0.5 \mathrm{~mL}$ of CH2Cl2 at rt for 20 h followed by work-up with saturated aqueous NaHCO3; b determined by $1 \mathrm{H}$ NMR using $\mathrm{CH} 2 \mathrm{Br} 2$ as internal standard.

We next explored of the scope of this reaction to demonstrate its utility (Scheme 2). While compound 15a could be isolated in 99\% yield with 2.5 equivalents of $\mathrm{TfOH}$, electron-richer and -poorer indoles also proved to be reactive, leading to 5-methyl and 6-chloro spiroindolines $\mathbf{1 5 b}$ and $\mathbf{1 5 c}$ in $99 \%$ yield. The nature of the nucleophilic arene was then studied. Switching from a para-tolyl to a para-anisyl group led uneventfully to $\mathbf{1 5 d}$ in $99 \%$ yield. Moving the methoxy group of the anisole to the meta position allowed to greatly increase the rate of the hydroarylation, leading to the fast formation of both para and ortho regioisomers 15ea/15eb $(87 \%)$ in a 2:1 ratio and $\mathbf{1 5 f a}(\mathbf{7 5 \%})$ as well as $\mathbf{1 5 f b}(13 \%)$ in a 5:1 ratio. A 2'-naphthyl group could also be employed as the internal nucleophile via its 1'-position, leading in $1 \mathrm{~h}$ to spiroindoline 15ga $(80 \%)$. Interestingly, performing this reaction in refluxing dichloroethane for a prolonged time ( $128 \mathrm{~h}$ ) delivered regioisomer $15 \mathrm{gb}(71 \%)$ via the reaction of the 3 '-position of the naphthyl group. It seems obvious that a retro Friedel-Crafts/Friedel-Crafts process from the kinetic product 15ga to the thermodynamic one 15gb is at play in this second set of reaction conditions. Using a less electron-rich phenyl nucleophile required a much higher (20 equivalents) loading of triflic acid as promotor to deliver 5-methoxyspiroindoline $\mathbf{1 5 h}$ (76\%) and 5-chlorospiroindoline $\mathbf{1 5 i}$ (99\%).

We then looked at the substitution of the indolic nitrogen and we were pleased to observed that both $N$-methyl and $N$-benzyl indoles were prone to deliver the respective spiroindolines $\mathbf{1 5 j}(70 \%)$ and $\mathbf{1 5 k}(99 \%)$, albeit in a significantly longer reaction time compared to the corresponding $\mathrm{N}-\mathrm{H}$ indoles. Of note, we only observed the para-regioisomers from the internal meta-methoxy phenyl nucleophile.

Aiming to investigate the 2'-benzofuryl group as an internal heteroaryl nucleophile, the expected spiroindoline $\mathbf{1 5 l}$ was produced in a poor yield, while $2^{\prime}, 2^{\prime}$-spirobenzofurane $\mathbf{1 8}$ was obtained as the major compound (69\%). In this case, the benzofurane was probably more easily protonated than the indole ring, generating an electrophilic benzofurane cation onto which the indole moiety could add as a nucleophile.

We were also eager to study the reactivity of 2-carbon-tethered substrates $1 \mathbf{m}-\mathbf{p}$ having in mind that: (1) the formation of the 5membered ring 3,3-spiroindolines 15m-p should be more difficult and (2) that the corresponding 6-membered ring tetracyclic compounds $\mathbf{1 6 m}-\mathbf{p}$ should be more likely formed. In order to observe any intramolecular hydroarylation of para-tolyl-containing $\mathbf{1 m}$, up to 20 equivalents of triflic acid had to be employed (Scheme 2). Gratifyingly, the C3-cyclization product $\mathbf{1 5 m}(99 \%)$ was exclusively obtained instead of the expected C2-cyclization product 16m. This result is in sharp contrast with previous results on related substrates (Scheme 1a, compounds 5) ${ }^{3 \mathrm{~b}-\mathrm{g}}$ including our own results with the corresponding $N$-Ac indoles (Scheme 1d; compounds 14) ${ }^{1{ }^{11 b}} \mathrm{~A}$ phenyl nucleophile was also competent to deliver spiroindoline 15n (70\%). Even more remarkably, upon running the reaction in pure $\mathrm{TfOH}$, the less electron-rich 5-bromo indole and para-fluorophenyl nucleophile delivered respectively spiroindolines $\mathbf{1 5 o}(99 \%)$ and 15p (82\%).

Intrigued by the regioselectivity observed for these 2-carbon-tethered substrates, we wondered what would be the outcome of an intermolecular reaction in terms of reactivity and regioselectivity. As already mentioned and confirmed here, $\mathrm{N}$-H-indoles have a high propensity to dimerize under acidic conditions ${ }^{3 \mathrm{a}}$ and the previously reported addition of external nucleophiles occurred at the C2-position (Scheme 1a; compound 6). ${ }^{3 \mathrm{~h}}$ Indeed, dimerization of 3-methylindole is mainly observed with a stoichiometric amount of $\mathrm{TfOH}$ in $\mathrm{CH}_{2} \mathrm{Cl}_{2}$. However, running the reaction in pure $\mathrm{TfOH}$ allowed us to observe, after $3.5 \mathrm{~h}$, the intermolecular hydroarylation of 3-methylindole with the addition of veratrole at the C3-position, leading to $\mathbf{1 5 q}$ in $90 \%$ yield. ${ }^{15}$ Once again, this C3-regioselectivity is in sharp contrast with what has been observed previously (Scheme 1a). Anisole, thioanisole, phenol, 2-naphtol and toluene were also competent nucleophiles under those conditions, leading respectively to 3 -arylindolines 15r-v. Bromobenzene was also sufficiently reactive to add to 3-methylindole, delivering 15w. Other 3-substituted indoles such as tryptophol and $N$-trifluoroacetyltryptamine were also prone to react with anisole to yield $\mathbf{1 5 x}, \mathbf{y}$. 
Scheme 2. Scope of the TfOH-mediated C3-regioselective hydroarylation of indoles.
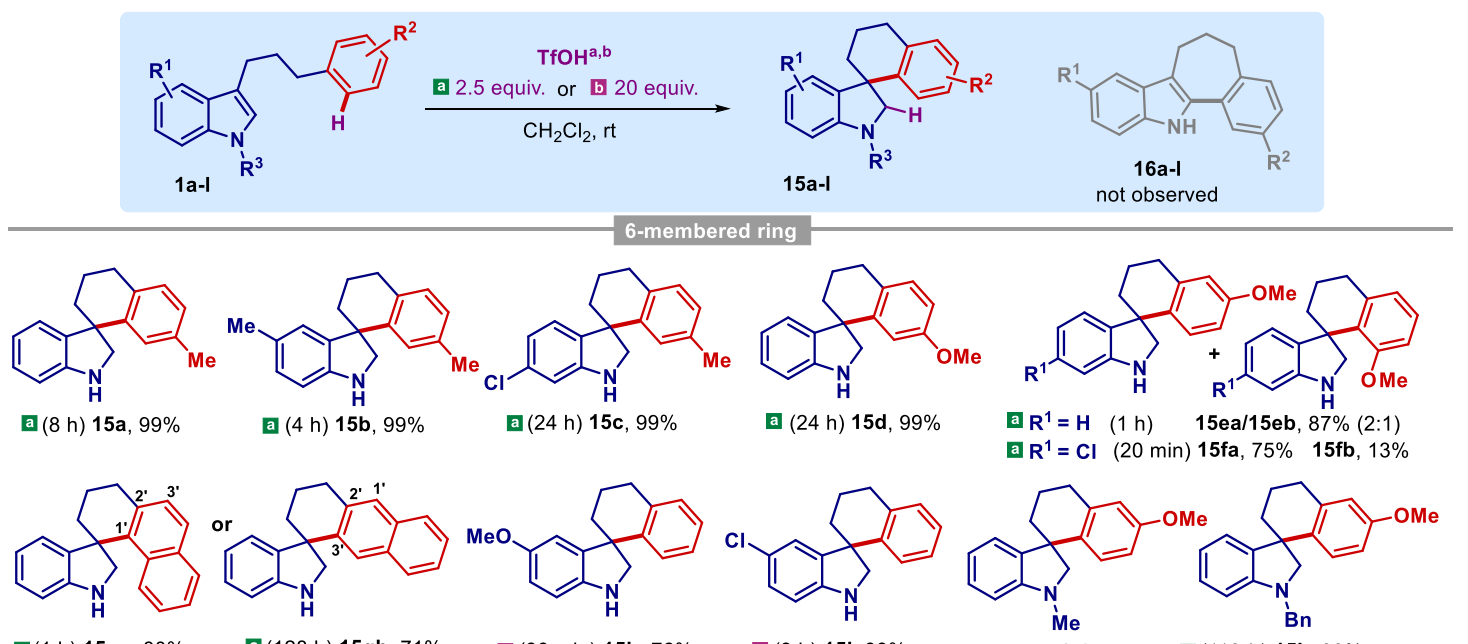

$\begin{array}{llllll}\text { a }(1 \mathrm{~h}) \mathbf{1 5} \mathbf{g a}, 80 \% & \mathbf{a}(128 \mathrm{~h}) \mathbf{1 5} \mathbf{g b}, \mathbf{7 1} \% & \text { b }(30 \mathrm{~min}) \mathbf{1 5 h}, 76 \% & \text { b }(3 \mathrm{~h}) \mathbf{1 5 i}, 99 \% & \text { a }(110 \mathrm{~h}) \mathbf{1 5 j}, \mathbf{7 0} \% & \mathbf{a}(110 \mathrm{~h}) \mathbf{1 5 k}, 99 \%\end{array}$
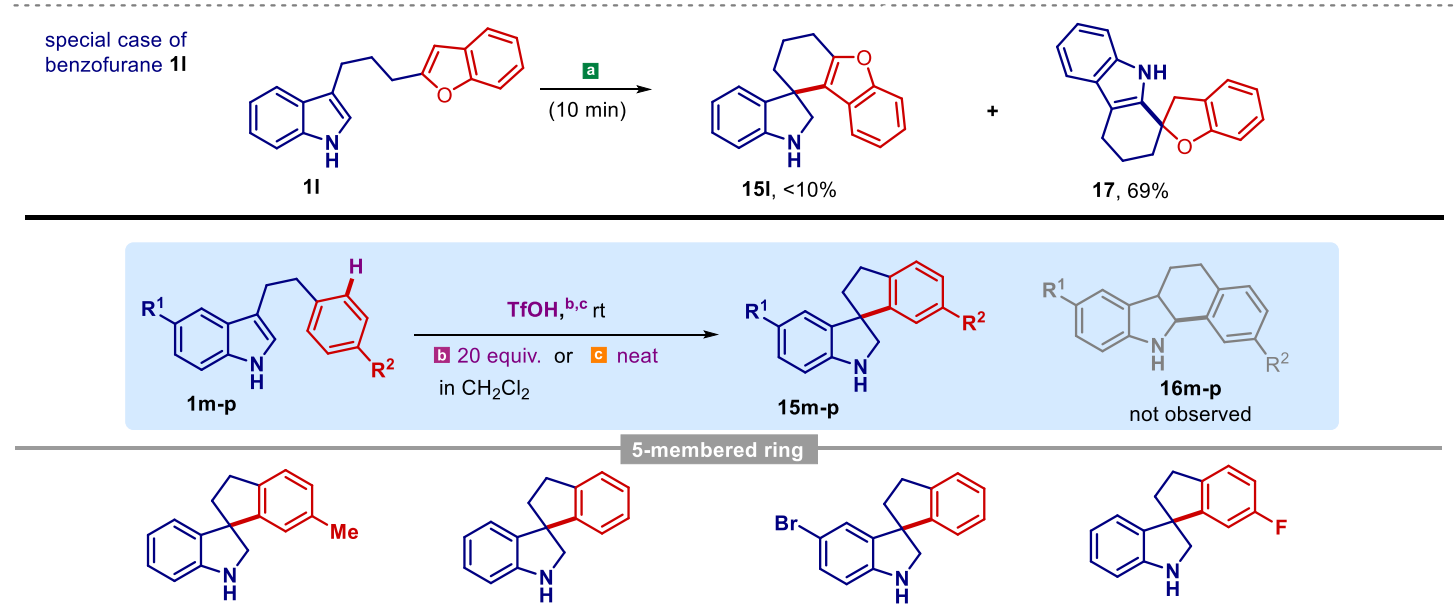

$\begin{array}{llll}\text { b }(40 \text { h) } 15 m, 99 \% & \text { b }(48 \text { h) } 15 n, 70 \% & \text { cc }(14 \text { h) } 150,99 \% & \text { cd (20 h) } 15 p, 82 \%\end{array}$
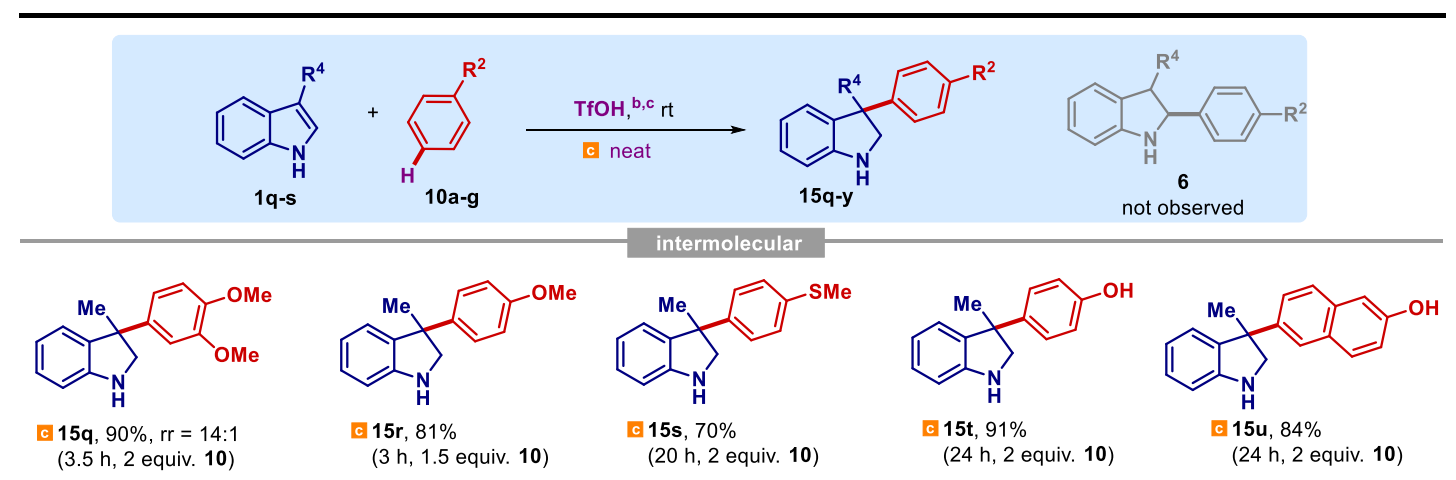

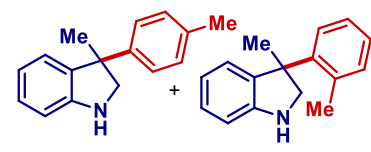

c] $15 \mathrm{va} / 15 \mathrm{vb}, 77 \%(4: 1)$

(20 h, 2 equiv. 10)

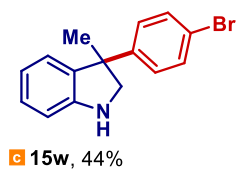

(24 h, 2 equiv. 10$)$

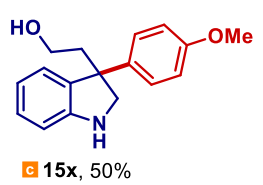

$(20 \mathrm{~h}, 3.5$ equiv. 10

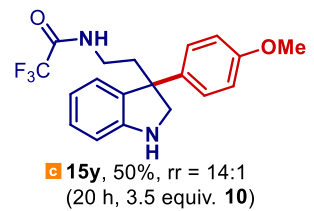

Reactions conditions: 0.1 mmol of 1a-p (intramolecular) or 0.25 mmol of 1q-s (intermolecular) and 2.5 equiv. TfOH (conditions a), 20 equiv. TfOH (conditions b) in $1 \mathrm{~mL}$ of $\mathrm{CH}_{2} \mathrm{Cl}_{2}$ or in pure TfOH $(0.5 \mathrm{~mL}$, conditions $c)$ at $\mathrm{rt}$, followed by work-up with saturated aqueous $\mathrm{NaHCO}_{3}(\mathrm{rr}=$ regioisomeric ratio, $\mathrm{rr}>14: 1$ unless otherwise noticed). 
From a mechanistic point of view, it seems evident that protonation at C2 occurs, generating a carbocation at C3 onto which the electron-rich arene adds to deliver the 3-aryl-indolines 15. These atypical C2-protonations of indoles have been known for decades using strong acids ${ }^{16}$ and demonstrated by isotopic exchanges, ${ }^{17}$ in particular when the indole ring is substituted at C3. It is also known that $\mathrm{C} 3$-substituted indoles undergo electrophilic substitutions at $\mathrm{C} 2 .{ }^{18}$ Finally, recent studies from our group revealed the coordination of $\mathrm{Au}(\mathrm{I})$ complexes at the $\mathrm{C} 2$-position is possible. ${ }^{19}$ Overall, reactions triggered by direct C2-nucleophilicity of indoles are often overlooked. ${ }^{20}$.

To explain the exquisite regioselectivity of the reaction towards C3-arylindolines $\mathbf{1 5}$ without observing intramolecular additions of the arene group to the $\mathrm{C} 2$-position, we first elaborated the following mechanistic hypothesis for the formation of the 6-membered 3,3-spiroindolines 15a-k in presence of 2.5 equivalents of $\mathrm{TfOH}$ (Scheme 3 ). Protonation at the C3-position of the enamine moiety of N-H indole 1 into iminium $\mathbf{1 8 A}$ and its mesomeric C2-carbocation 18B would likely be kinetically favored over C2 protonation into 19A/B. Intermolecular Friedel-Crafts reaction of $\mathbf{1 8 B}$ with another molecule of indole $\mathbf{1}$ would lead to dimer $\mathbf{4} \cdot \mathbf{T f O H}$ as a triflic acid salt. However, an excess of triflic acid could promote a retro Friedel-Crafts reaction of $\mathbf{4} \cdot \mathbf{T f O H}$, regenerating 1 via $\mathbf{1 8} .^{21}$ Reversible protonation of $\mathbf{1}$ could also generate extended iminium 19A with C3-carbocation 19B as its resonance form, which could be intramolecularly trapped into 3,3-spiroindoline triflic acid salt $\mathbf{1 5} \cdot \mathbf{T f O H}$, which is the postulated thermodynamically favored product.

\section{Scheme 3. Mechanistic hypothesis for the C3-intramolecular hydroarylation leading to 6-membered spiroindolines 15a-l.}

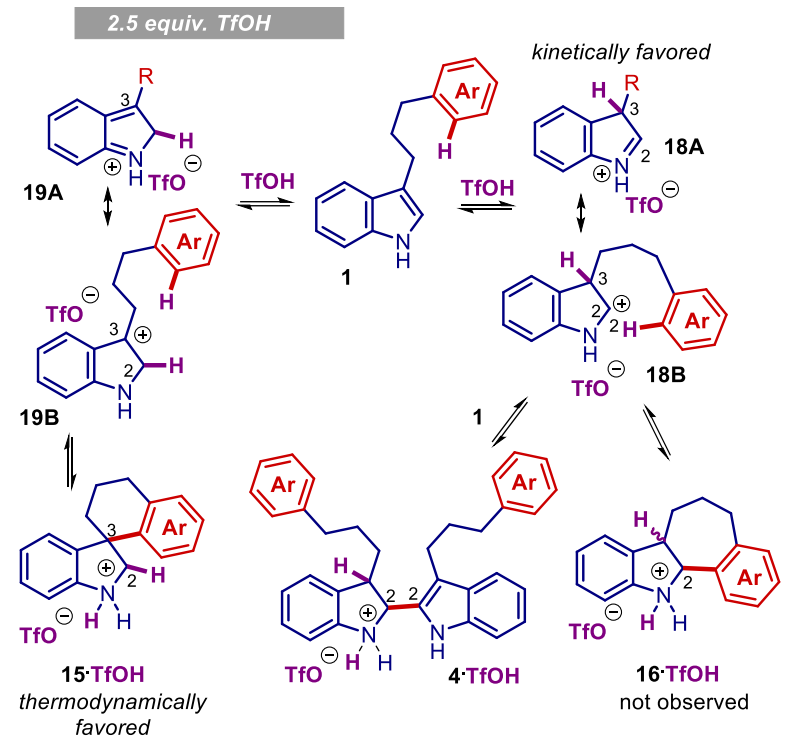

To gain more insights, we performed a DFT study, which is fully described in the Supporting Information. Geometries were optimized at the M06-2X level of theory. All atoms were described by the 6-311+G(d,p) basis set. The values discussed are Gibbs free energies $\left(\Delta G_{298}, \mathrm{kcal} / \mathrm{mol}\right)$ including PCM solvation correction. The 3-carbon-tethered arylindoles $\mathbf{1 a}$ and the 2-carbon tethered arylindoles $\mathbf{1 n}$ were used as model substrates. Starting with $\mathbf{1 a}$, we computed the relative stability of the possible products $\mathbf{1 5 a}$, 16a and $\mathbf{4 a}$ (Scheme 4). Interestingly, we found that none of these compounds are more stable than the starting material. In particular, the experimentally isolated spiro product 15a is less stable than $1 \mathbf{a}$ by $1.9 \mathrm{kcal} / \mathrm{mol}$, a result that was confirmed using various levels of theory. Even the dimer 4a was found less stable than two monomers. Since the reaction is performed in the presence of an excess of TfOH, we then computed the free energy of the corresponding triflate salts. This time, the reaction of 1a with TfOH, giving either the spiro compound $\mathbf{1 5} \cdot \mathbf{T f O H}$, the cis or trans 7 -membered ring products $\mathbf{1 6} \cdot \mathbf{T f O H}$, or the dimer $\mathbf{4 a} \cdot \mathbf{T f O H}$, is exergonic. Therefore, the success of the reaction is likely due to the acidity of the medium and the isolation of the spiro compounds should be the fruit of the neutralization of the triflate salts by the work-up with saturated aqueous $\mathrm{NaHCO}_{3}$. 
Scheme 4. Free energy of the products from 3-carbon-tethtered indole 1a $\left(\Delta G_{298}, \mathrm{kcal} / \mathrm{mol} ; \mathrm{R}=\left(\mathrm{CH}_{2}\right)_{3}-p\right.$-tolyl $)$.

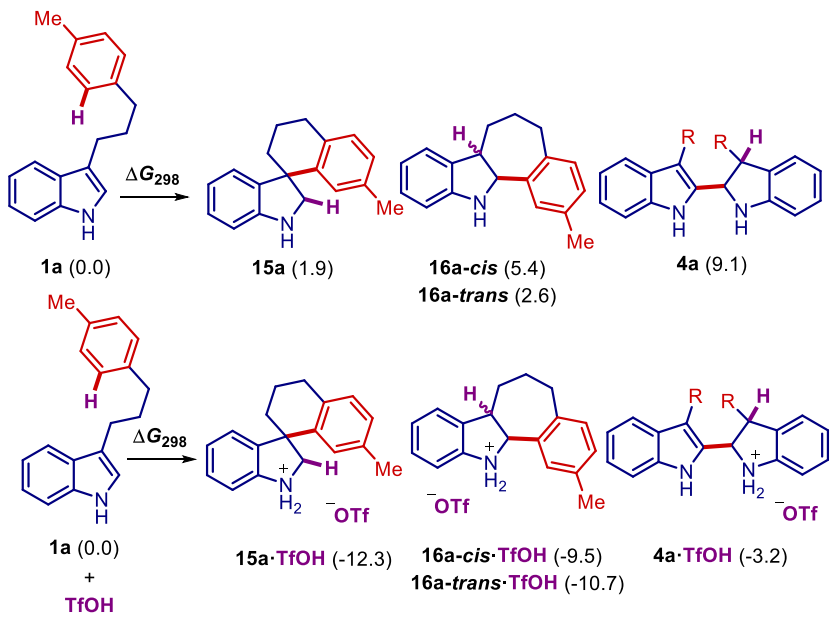

We then studied the reaction pathways. By using one explicit TfOH molecule in the computations (not shown, see the SI for details), we found that the kinetically favored pathway is the formation of the dimer $\mathbf{4 a} \cdot \mathbf{T f O H}$, but it is easily reversible. The spiro derivative $\mathbf{1 5 a} \cdot \mathbf{T f O H}$ is favored thermodynamically over all species (Scheme 4), but also kinetically over the 7-membered ring products (TS of $26.0 \mathrm{kcal} / \mathrm{mol}$ ). While in line with the experimental results for 1a, at least two equivalents of triflic acid are necessary to observe the formation of indoline 15a experimentally (Table 1), which led us to introduce more explicit TfOH molecules in analogy with the recently demonstrated stabilizing effect of hydrogen bond acid-HFIP clusters. ${ }^{15,22}$ The H-bonded (TfOH) $)_{2}$ dimer ${ }^{23}$ was used to model reactions promoted by 2.5 equiv of $\mathrm{TfOH}$ and the cyclization barrier was significantly lowered compared to the use of only one molecule of TfOH. The computed formation of $\mathbf{1 5 a} \cdot \mathbf{T f O H}$ is shown in Figure 1 (left part).

Figure 1. Free energy profile for the formation of $\mathbf{1 5 a} \cdot \mathbf{T f O H}$ and $\mathbf{1 6 a}-\mathbf{c i s} \cdot \mathbf{T f O H}$ using 2 equiv of TfOH $\left(\Delta G_{298}, \mathrm{kcal} / \mathrm{mol}\right)$; geometries of the transitions states (blue $=\mathrm{N}$; red $=\mathrm{O}$; yellow $=\mathrm{S}$; green $=\mathrm{F}$ ).

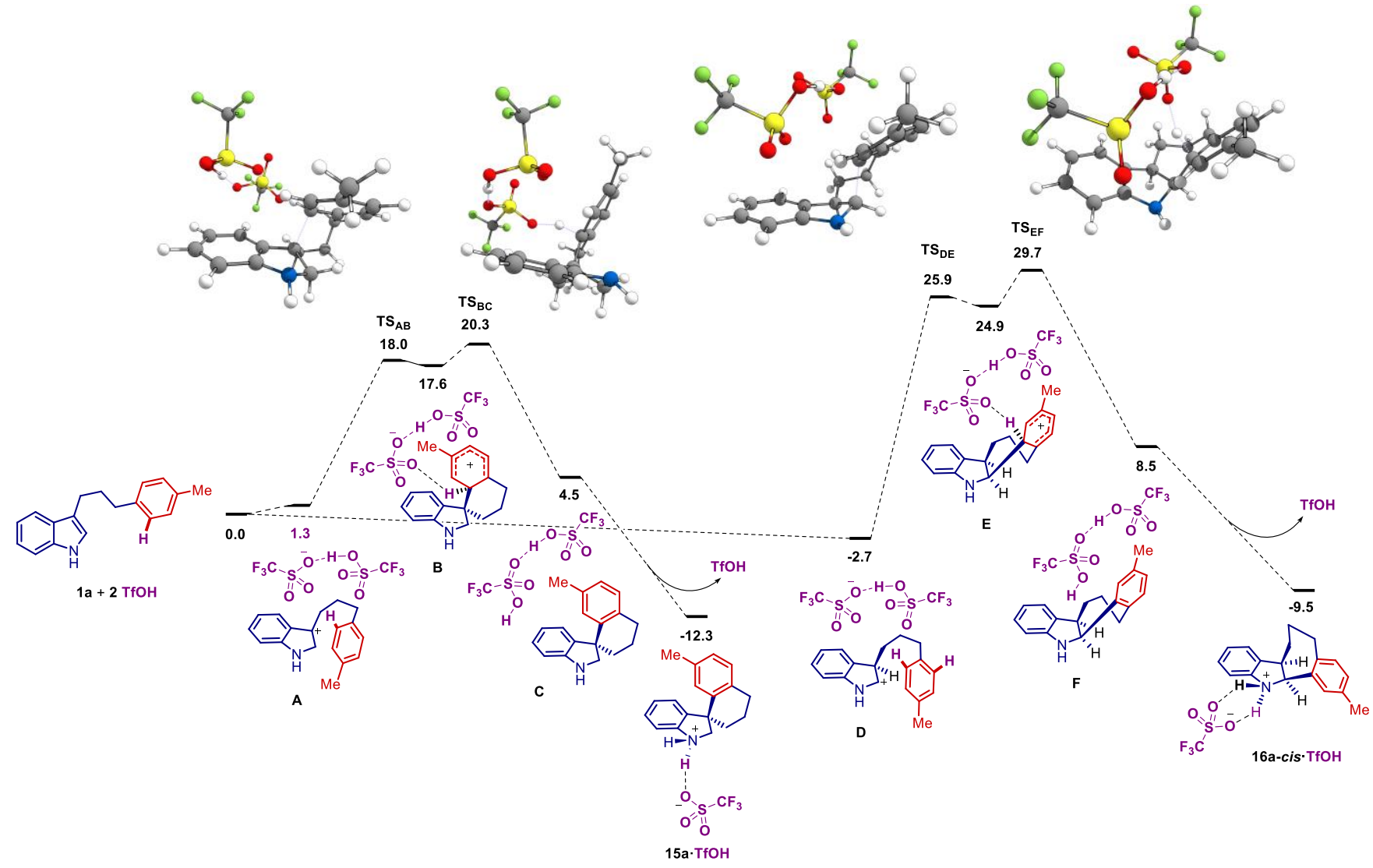

Protonation at $\mathrm{C} 2$ to give $\mathbf{A}$ is endergonic by $1.3 \mathrm{kcal} / \mathrm{mol}$. Nucleophilic attack of the $p$-tolyl group to the carbocationic center takes place through $\mathbf{T} \mathbf{S}_{\mathbf{A B}}$, lying at $18.0 \mathrm{kcal} / \mathrm{mol}$ on the free energy surface. It leads to the Wheland-type intermediate $\mathbf{B}$ at $17.6 \mathrm{kcal} / \mathrm{mol}$. Deprotonation is the rate-determining step, $\mathbf{T S}_{\mathbf{B C}}$ being found at $20.3 \mathrm{kcal} / \mathrm{mol}$. As discussed above, the corresponding spiro derivative $\mathbf{C}$ is less stable than the reactants (by $4.5 \mathrm{kcal} / \mathrm{mol}$ in the presence of the $(\mathrm{TfOH})_{2}$ dimer). However, moving one TfOH to the indoline 
nitrogen atom places $\mathbf{1 5} \cdot \mathbf{T} \cdot \mathbf{T O H}$ at $-12.3 \mathrm{kcal} / \mathrm{mol}$. In contrast with the $\mathrm{C} 2$ protonation, the protonation at $\mathrm{C} 3$ is exergonic (Figure 1 , right part: $\mathbf{D},-2.7 \mathrm{kcal} / \mathrm{mol})$. However, the $\mathrm{SE}_{\mathrm{Ar}}$ process involves transition states that are clearly higher in energy than the previously computed ones (TS $25.9 \mathrm{kcal} / \mathrm{mol}$; TS $\mathbf{T S F}_{\text {EF }} 29.7 \mathrm{kcal} / \mathrm{mol}$ ). Overall, despite a protonation equilibrium probably shifted toward the C3 side, the minor C2-protonated species A may be the main productive species in excess of TfOH.

In contrast, DFT computations of the cyclization of 2-carbon-tether indole $1 \mathbf{n}$ indicated that the related pathway via the sole protonation of the $\mathrm{C} 2=\mathrm{C} 3$ bond favored the cyclization at $\mathrm{C} 2$ into 6-membered ring fused indoline $\mathbf{1 6 n} \cdot \mathbf{T f O H}$ over cyclization at $\mathrm{C} 3$ into 5 membered spiroindoline 15n·TfOH even with two explicit TfOH molecules. Moreover, unlike the previous series, the spiro derivative $\mathbf{1 5 n} \cdot \mathbf{T f O H}$ is not the most stable isomer. This time, the unobserved 16n-cis $\cdot \mathbf{T f O H}$ is clearly the thermodynamic product (Scheme 5).

Scheme 5. Free energy of the products from 2-carbon-tethtered indole $1 \mathrm{n}\left(\Delta G_{298}, \mathrm{kcal} / \mathrm{mol} ; \mathrm{R}=\left(\mathrm{CH}_{2}\right)_{2}-\mathrm{Ph}\right)$.

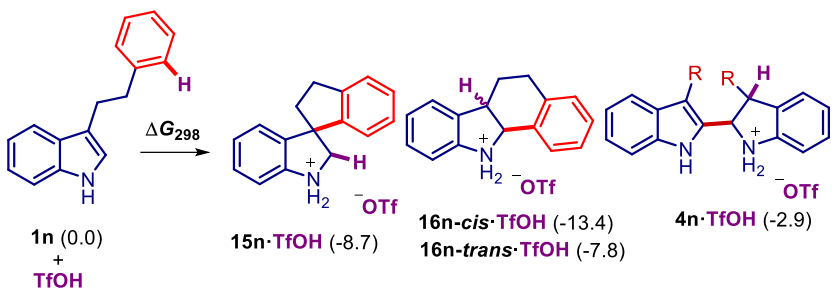

Importantly, the cyclization into the 5-membered-ring 3,3-spiroindolines $\mathbf{1 5} \mathbf{m}-\mathbf{p}$ and the intermolecular reaction leading to indolines 15q-y requires experimentally a very large excess of $\mathrm{TfOH}$ (20 equivalents or more).

To account for the formation of $\mathbf{1 5 n - y}$ in the presence of a large excess of acid, an alternative mode of activation of the indole with TfOH was therefore investigated. In these superacidic conditions, superelectrophilic species could be generated. ${ }^{23,24}$ Double protonation of the indole might occur at both the nitrogen position and at C2 or C3, leading respectively to diprotonated species $\mathbf{2 0}$ and $\mathbf{2 1}$ (Scheme 6). We reasoned that if the excess of TfOH encourages the protonation of the indole nitrogen atom, this would disfavor the protonation at C3 (1,2-dication 20) to avoid two contiguous positive charges. By switching off this pathway, only the 3-arylated indolines $\mathbf{1 5} \cdot \mathbf{T f O H}$ would be obtained after $\mathrm{C} 2$ protonation (1,3-dication $\mathbf{2 1}$ ) and addition of arene $\mathbf{1 0 .}$

\section{Scheme 6. Mechanistic hypothesis for the regioselective inter- and intramolecular C3-hydroarylation leading to indolines} 15q-l and 5-membered-ring spiroindolines 15m-p.

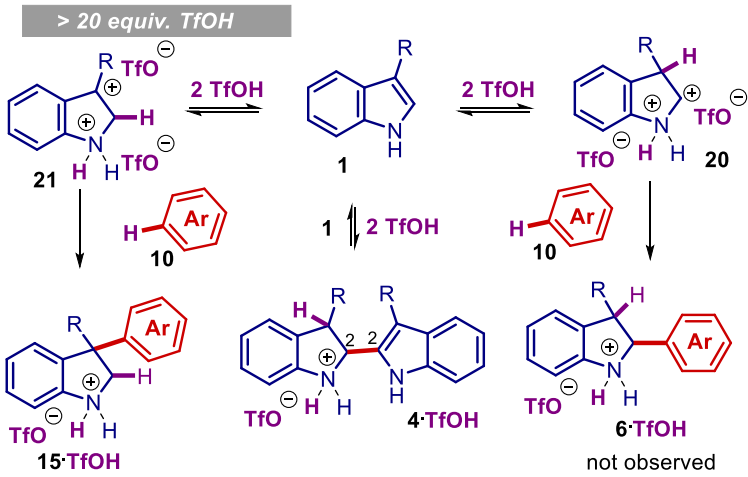

This hypothesis involving a dicationic intermediate was investigated by DFT computations for the cyclization of $\mathbf{1 n}$ into $\mathbf{1 5 n}$. Interestingly, it was not possible to compute the formation of a 6-membered ring product from a 1,2-dication that would arise from the protonation at $\mathrm{C} 3$, giving credit to the working hypothesis. In such case, $\mathrm{TfOH}$ was ejected from the protonated indole nitrogen atom during optimization. On the other hand, keeping one TfOH bonded to the indole nitrogen atom, it was possible to optimize the 1,3dication and its pathway towards $\mathbf{1 5 n}$ with an activation barrier of $35.8 \mathrm{kcal} / \mathrm{mol} .{ }^{25}$ While the 1,3 -dication hypothesis is in line with the spiro selectivity, it does not by itself explain how the reaction could take place at room temperature. We reasoned that a strongly polar environment could stabilize the 1,3-dication. ${ }^{22,15}$ Therefore, more explicit TfOH molecules were added and once again the computed cyclization barrier was dramatically lowered (Figure 2) ${ }^{23}$ By adding two TfOH to the upper triflate via hydrogen bonds, a strong stabilization of dication $\mathbf{G}$ was observed. Remarkably, this species was found more stable than the reactants (-1.4 kcal/mol), which can be attributed to the strongly polar environment provided by the $(\mathrm{TfOH})_{3}$ cluster. The free energy of the cyclization transition state $\mathbf{T} \mathbf{S}_{\mathbf{G H}}$ is only $15.6 \mathrm{kcal} / \mathrm{mol}$. The corresponding Wheland intermediate also enjoys a strong stabilization $(\mathbf{H} ; 6.9 \mathrm{kcal} / \mathrm{mol})$ and the deprotonation transition state could be found only $2.6 \mathrm{kcal} / \mathrm{mol}$ above it (TSHI; $9.5 \mathrm{kcal} / \mathrm{mol}$ ). Of course the exact nature of the $(\mathrm{TfOH})_{\mathrm{x}}$ clusters in the biphasic $\mathrm{TfOH} / \mathrm{CH}_{2} \mathrm{Cl}_{2}$ mixture (or neat $\mathrm{TfOH}$ ) is not known, but there is a clear trend in the computations supporting the idea of the formation of a 1,3-dication stabilized by such supramolecular assemblies. 
Figure 2. Free energy profile for the formation of $\mathbf{1 5 n} \cdot \mathbf{T f O H}$ in the presence of 4 molecules of TfOH $\left(\Delta G_{298}, \mathrm{kcal} / \mathrm{mol}\right)$; geometries of the transitions states $($ blue $=\mathrm{N}$; red $=\mathrm{O}$; yellow $=\mathrm{S}$; green $=\mathrm{F}$ ).

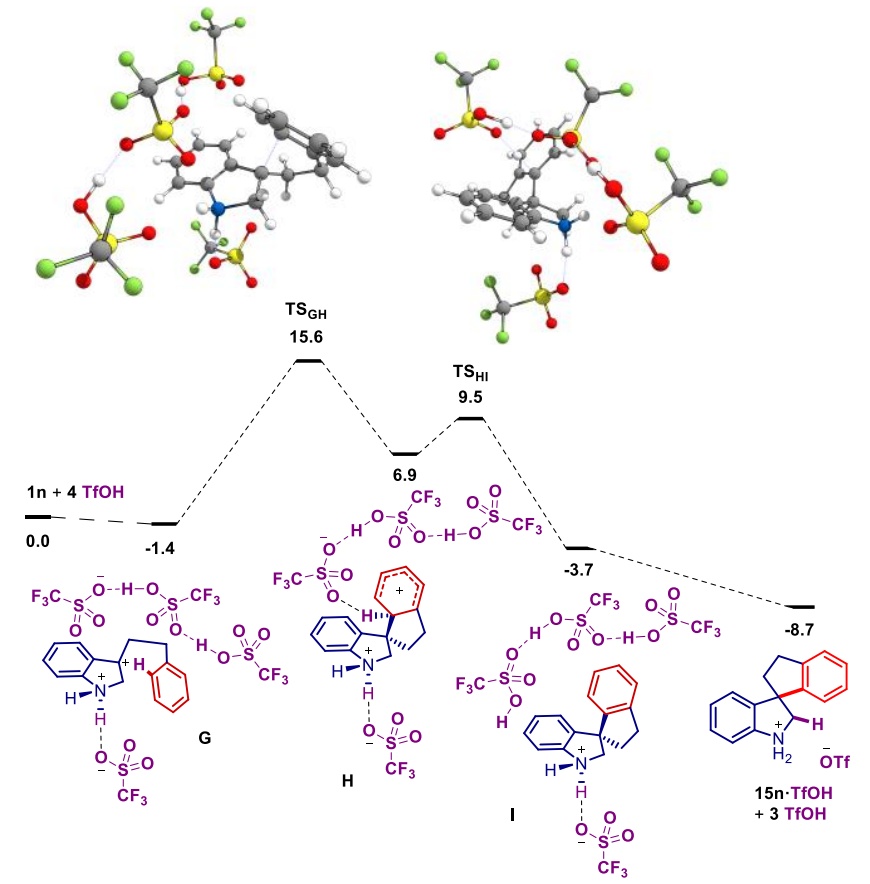

To summarize, the above computations show that the reaction is viable because the experimental conditions lead to ammonium triflates, hence the requirement of an excess of $\mathrm{TfOH}$. The corresponding neutral products are actually less stable than the reactants. The formation of dimer $\mathbf{4} \cdot \mathbf{T f O H}$ of the starting indole is the kinetically favored process via protonation at the C3-position of the enamine moiety of N-H indole $\mathbf{1}$ into iminium 18, yet it is easily reversible. It is therefore not surprising to observe such dimers, but they can be disassembled in favor of the more stable 3-arylindolines $\mathbf{1 5} \cdot \mathbf{T f O H}$. The preferred C3- over C2-arylation seems inconsistent with the preferential C3-protonation of the indole. However, even if C2-protonation is an endergonic process, arylation at C3 can be funneled nonetheless for several reasons that can be deduced from the computations:

(i) Reactions with 2.5 equiv of TfOH: For intramolecular arylations of 3-carbon-tethered arylindoles 1a-l, the formation of a 6-membered ring is entropically favored over a 7-membered ring one. Thus, the 6-membered ring pathway leading to a spiro derivative 15aI prevails and compensates the endergonic C2-protonation. Moreover, the use of 2.5 equiv of TfOH allows the formation of a $\mathrm{H}$ bonded $(\mathrm{TfOH})_{2}$ dimer which greatly stabilizes the cationic intermediates and transition states. For intramolecular arylations of 2 carbon-tethered arylindoles $\mathbf{1 m}$-p, the formation of a 6-membered ring can only result from a C2-arylation. However, even if the $(\mathrm{TfOH})_{2}$ dimer is taken into account in the computations, a high barrier is expected.

(ii) Reactions with $\geq 20$ equiv of TfOH: For intramolecular arylations of 2-carbon-tethered arylindoles 1m-p and intermolecular reactions of 1q-s, C3-arylation can be enforced by protonating the indole nitrogen atom, which prevents C3-protonation to avoid a 1,2-dication. The protonation then takes place at $\mathrm{C} 2$ and the $\mathrm{C} 3$-arylation benefits from a strong stabilization of the cationic intermediates and transition states by the highly polar environment offered by the $\mathrm{H}$-bonded $(\mathrm{TfOH})_{\mathrm{n}}$ cluster. ${ }^{22,23}$

In conclusion, we demonstrated that the regioselective dearomative inter- and intramolecular 3-hydroarylation of indoles could be performed without the need of a deactivating acetyl group and leads efficiently to the 3-arylindolines and 5- or 6-membered 3,3spiroindolines. This redox-neutral addition of a nucleophile to the $\mathrm{C} 3$-position of $\mathrm{N}-\mathrm{H}$ or $\mathrm{N}$-alkyl indoles is very rare and is in sharp contrast with the usual $\mathrm{C} 2$-addition of a nucleophile to the transient $\mathrm{C} 2$-iminium generated by isomerization of the enamine moiety of $\mathrm{N}-\mathrm{H}$ or $\mathrm{N}$-alkyl indoles. This unique atom economical transformation based on Umpolung of indoles only requires triflic acid at room temperature, which makes this methodology operationally simple and practical. A DFT investigation suggests the involvement of C3-cationic or 1,3-dicationic intermediates stabilized by $\mathrm{H}$-bonded $(\mathrm{TfOH})_{\mathrm{n}}$ clusters.

We thank the CHARMMMAT Laboratory of Excellence (ANR-11-LABX0039) for funding of the post-doctoral position of N.S. and the China Scholarship Council for the PhD scholarship of W.S. We also acknowledge Université Paris-Saclay, the CNRS and Ecole polytechnique for financial support. This work was granted access to the HPC resources of CINES under the allocation 2020-A0070810977 made by GENCI.

\section{References}

(1) (a) Sundberg, R. J. Electrophilic Substitution Reactions of Indoles. In Heterocyclic Scaffolds II:; Gribble, G. W., Ed.; Topics in Heterocyclic Chemistry; Springer Berlin Heidelberg, 2010; pp 47-115. (b) Lakhdar, S.; Westermaier, M.; Terrier, F.; Goumont, R.; Boubaker, T.; Ofial, A. R.; Mayr, H., Nucleophilic Reactivities of Indoles. J. Org. Chem. 2006, 71, 9088-9095. http://dx.doi.org/10.1021/jo0614339. 
(2) For a review on indole dearomatization: Roche, S. P.; Youte Tendoung, J.-J.; Tréguier, B. Advances in Dearomatization Strategies of Indoles. Tetrahedron 2015, 71 (22), 3549-3591. https://doi.org/10.1016/j.tet.2014.06.054.

(3) With Brønsted acids: (a) Smith, G. F.; Walters, A. E. 194. Indoles. Part V. 3-Alkylindole Dimers. J. Chem. Soc. 1961, 940-943. https://doi.org/10.1039/JR9610000940; (b) Pelcman, B.; Gribble, G. W. Total Synthesis of the Marine Sponge Pigment Fascaplysin. Tetrahedron Lett. 1990, 31 (17), 2381-2384. https://doi.org/10.1016/S0040-4039(00)97367-2; (c) Bergman, J.; Koch, E.; Pelcman, B. Reactions of Indole-3-Acetic Acid Derivatives in Trifluoroacetic Acid. Tetrahedron Lett. 1995, 36 (22), 3945-3948. https://doi.org/10.1016/00404039(95)00648-V; (d) Gilbert, E. J.; Van Vranken, D. L. Control of Dissymmetry in the Synthesis of (+)-Tjipanazole F2. J. Am. Chem. Soc. 1996, 118 (23), 5500-5501. https://doi.org/10.1021/ja9608959; (e) Lakatosh, S. A.; Luzikov, Y. N.; Preobrazhenskaya, M. N. Synthesis of 4-Substituted 3-(Indol-3-yl)Maleimides and Azepines with Annelated Indole and Maleimide Nuclei. Tetrahedron 2005, 61 (34), 8241-8248. https://doi.org/10.1016/j.tet.2005.06.027; (f) Ciccolini, C.; Mari, M.; Lucarini, S.; Mantellini, F.; Piersanti, G.; Favi, G. Polycyclic Indolines by an Acid-Mediated Intramolecular Dearomative Strategy: Reversing Indole Reactivity in the Pictet-Spengler-Type Reaction. Adv. Synth. Catal. 2018, 360 (21), 4060-4067. https://doi.org/10.1002/adsc.201800981; (g) Cui, H.-L.; Liu, S.-W.; Xiao, X. Synthesis of Tetrahydroindolizino[8,7-b]Indole Derivatives in the Presence of Fe(OTf)3 or CF3SO3H through Intramolecular Dearomatization of Indole. J. Org. Chem. 2020, 85 (23), 15382-15395. https://doi.org/10.1021/acs.joc.0c02188; (h) Charlet-Fagnère, C.; Laronze, J.; Laronze, J.-Y.; Toupet, L.; Vistelle, R.; Lamiable, D.; Mouchard, C.; Renard, P.; Adam, G. Etude de la dimerisation en milieu acide de la melatonine (5-methoxy-Nacetyltryptamine) et de quelques derives apparentes. Oxydation de 2-arylindolines en 2-arylindoles. Bull. Soc. Chim. Fr. 1996, 1 (133), 3950; with Lewis acids: (i) Bubnov, Y. N.; Zhun', I. V.; Klimkina, E. V.; Ignatenko, A. V.; Starikova, Z. A. Reductive 1,2-Allylboration of Indoles by Triallyl- and Triprenylborane - Synthesis of 2-Allylated Indolines. Eur. J. Org. Chem. 2000, (19), 3323-3327. https://doi.org/10.1002/1099-0690(200010)2000:19<3323::AID-EJOC3323>3.0.CO;2-K; (j) Han, B.; Xiao, Y.-C.; Yao, Y.; Chen, Y.-C. Lewis Acid Catalyzed Intramolecular Direct Ene Reaction of Indoles. Angew. Chem. Int. Ed. 2010, 49 (52), 10189-10191. https://doi.org/10.1002/anie.201005296; (k) Nowrouzi, F.; Batey, R. A. Regio- and Stereoselective Allylation and Crotylation of Indoles at C2 Through the Use of Potassium Organotrifluoroborate Salts. Angew. Chem. Int. Ed. 2013, 52 (3), $892-895$. https://doi.org/10.1002/anie.201207978; from N-acyl indoles: (1) Wang, J.-J.; Zhou, A.-X.; Wang, G.-W.; Yang, S.-D. An Aluminum Triflate-Catalyzed Intramolecular Reaction Sequence Toward Concise Construction of the Tetrahydropyrido[1,2-a]Indol-6-One Skeleton. Adv. Synth. Catal. 2014, 356 (16), 3356-3362. https://doi.org/10.1002/adsc.201400391; (m) Morimoto, N.; Morioku, K.; Suzuki, H.; Takeuchi, Y.; Nishina, Y. Lewis Acid and Fluoroalcohol Mediated Nucleophilic Addition to the C2 Position of Indoles. Org. Lett. 2016, 18 (9), 2020 2023. https://doi.org/10.1021/acs.orglett.6b00629; (n) Hartmann, J. M.; de Groot, M.; Schäringer, K.; Henke, K.; Rissanen, K.; Albrecht, M. 2H-[1,3]Oxazino[3,2- $]$ Indolin-4(3H)-Ones: A Class Of Polyheterocyclic Indole-Based Compounds. Eur. J. Org. Chem. 2018, 2018 (7), 901-907. https://doi.org/10.1002/ejoc.201701630; (o) Yao, Z.; Feng, H.; Xi, H.; Xi, C.; Liu, W. CF3SO3H-Enabled Cascade Ring-Opening/Dearomatization of Indole Derivatives to Polycyclic Heterocycles. Org. Biomol. Chem. 2021, 19, $4469-4473$. https://doi.org/10.1039/D1OB00712B; (p) Zhang, J.; Xia, W.; Huda, S.; Ward, J. S.; Rissanen, K.; Albrecht, M. Synthesis of N-Fused Indolines via Copper (II)-Catalyzed Dearomatizing Cyclization of Indoles. Adv. Synth. Catal. 2021, 363 (12), $3121-03126$. https://doi.org/10.1002/adsc.202100290.

(4) For an account: Abou-Hamdan, H.; Kouklovsky, C.; Vincent, G. Dearomatization Reactions of Indoles to Access 3D Indoline Structures. Synlett 2020, 31 (18), 1775-1788. https://doi.org/10.1055/s-0040-1707152.

(5) For reviews on electrophilic indoles: (a) Cerveri, A.; Bandini, M. Recent Advances in the Catalytic Functionalization of "Electrophilic" Indoles. Chin. J. Chem. 2020, 38 (3), 287-294. https://doi.org/10.1002/cjoc.201900446; (b) Bandini, M. Electrophilicity: The "Dark-Side" of Indole Chemistry. Org. Biomol. Chem. 2013, 11 (32), 5206-5212. https://doi.org/10.1039/C3OB40735G.

(6) Nishida, K.; Yanase, E.; Nakatsuka, S.-i. Nucleophilic Addition of Benzene Derivatives to the 3-Position of N-Acyl-3-Alkylindole. ITE, Lett. on Batteries, New Technol. Med. 2006, 7, 59-62.

(7) (a) Beaud, R.; Guillot, R.; Kouklovsky, C.; Vincent, G. FeCl3-Mediated Friedel-Crafts Hydroarylation with Electrophilic N-Acetyl Indoles for the Synthesis of Benzofuroindolines. Angew. Chem. Int. Ed. 2012, 51 (50), 12546-12550. https://doi.org/10.1002/anie.201206611; (b) Beaud, R.; Guillot, R.; Kouklovsky, C.; Vincent, G. Regioselective Hydroarylation Reactions of C3 Electrophilic N-Acetylindoles Activated by FeCl3: An Entry to 3-(Hetero)Arylindolines. Chem. - Eur. J. 2014, 20 (24), 7492-7500. https://doi.org/10.1002/chem.201400284.

(8) Nandi, R. K.; Guillot, R.; Kouklovsky, C.; Vincent, G. Synthesis of 3,3-Spiroindolines via FeCl3-Mediated Cyclization of Aryl- or AlkeneContaining 3-Substituted N-Ac Indoles. Org. Lett. 2016, 18 (8), 1716-1719. https://doi.org/10.1021/acs.orglett.6b00174.

(9) For a review on the dearomative synthesis of 3-aryl indolines: Denizot, N.; Tomakinian, T.; Beaud, R.; Kouklovsky, C.; Vincent, G. Synthesis of 3-Arylated Indolines from Dearomatization of Indoles. Tetrahedron Lett. 2015, 56 (30), 4413-4429. https://doi.org/10.1016/j.tetlet.2015.05.078. For selected examples: (b) Trammel, G. L.; Kuniyil, R.; Crook, P. F.; Liu, P.; Brown, M. K. Nickel-Catalyzed Dearomative Arylboration of Indoles: Regioselective Synthesis of C2- and C3-Borylated Indolines. J. Am. Chem. Soc. 2021, 143 (40), 16502-16511. https://doi.org/10.1021/jacs.1c05902; (c) Wu, K.-J.; Dai, L.-X.; You, S.-L. Palladium(0)-Catalyzed Dearomative Arylation of Indoles: Convenient Access to Spiroindolenine Derivatives. Org. Lett. 2012, 14 (14), 3772-3775. https://doi.org/10.1021/ol301663h; (d) Zhu, S.; MacMillan, D. W. C. Enantioselective Copper-Catalyzed Construction of Aryl Pyrroloindolines via an Arylation-Cyclization Cascade. J. Am. Chem. Soc. 2012, 134 (26), 10815-10818. https://doi.org/10.1021/ja305100g; (e) Eastman, K.; Baran, P. S. A Simple Method for the Direct Arylation of Indoles. Tetrahedron 2009, 65 (16), 3149-3154 https://doi.org/10.1016/j.tet.2008.09.028; (f) Flanagan, S. R.; Harrowven, D. C.; Bradley, M. Radical Cyclisation Reactions with Indoles. Tetrahedron Lett. 2003, 44 (9), 1795-1798. https://doi.org/10.1016/S0040-4039(03)00094-7; (g) Burgett, A. W. G.; Li, Q.; Wei, Q.; Harran, P. G. A Concise and Flexible Total Synthesis of (-)-Diazonamide A. Angew. Chem. Int. Ed. 2003, 42 (40), 4961-4966. https://doi.org/10.1002/anie.200352577.

(10) Beaud, R.; Nandi, R. K.; Perez-Luna, A.; Guillot, R.; Gori, D.; Kouklovsky, C.; Ghermani, N.-E.; Gandon, V.; Vincent, G. Revealing the Electrophilicity of N-Ac Indoles with FeCl3: A Mechanistic Study. Chem. Commun. 2017, 53 (43), 5834-5837. https://doi.org/10.1039/C7CC02756G.

(11) For others transformations based on the activations of N-Ac indoles with $\mathrm{FeCl}_{3}$ : (a) Tomakinian, T.; Guillot, R.; Kouklovsky, C.; Vincent, G. Direct Oxidative Coupling of N-Acetyl Indoles and Phenols for the Synthesis of Benzofuroindolines Related to Phalarine. Angew. Chem. Int. Ed. 2014, 53 (44), 11881-11885. https://doi.org/10.1002/anie.201404055; (b) Nandi, R. K.; Ratsch, F.; Beaud, R.; Guillot, R.; Kouklovsky, C.; Vincent, G. Intermolecular Dearomative C2-Arylation of N-Ac Indoles Activated by FeCl3. Chem. Commun. 2016, 52 (30), $5328-5331$. https://doi.org/10.1039/C6CC01654E; (c) Marques, A.-S.; Coeffard, V.; Chataigner, I.; Vincent, G.; Moreau, X. Iron-Mediated Domino Interrupted Iso-Nazarov/Dearomative $(3+2)$-Cycloaddition of Electrophilic Indoles. Org. Lett. 2016, 18 (20), 5296-5299. https://doi.org/10.1021/acs.orglett.6b02613; (d) Wu, J.; Nandi, R. K.; Guillot, R.; Kouklovsky, C.; Vincent, G. Dearomative Diallylation of N-Acylindoles Mediated by FeCl3. Org. Lett. 2018, 20 (7), 1845-1848. https://doi.org/10.1021/acs.orglett.8b00361; (e) Zhang, J.; Li, J.; 
Ward, J. S.; Truong, K.-N.; Rissanen, K.; Albrecht, M. Iron(III) Chloride as a Mild Catalyst for the Dearomatizing Cyclization of N-Acylindoles. J. Org. Chem. 2020, 85 (19), 12160-12174. https://doi.org/10.1021/acs.joc.0c01373; (f) Luo, M.; Zhu, X.; Liu, R.; Yu, S.; Wei, W. FeCl3-Promoted Annulation of 2-Haloindoles: Switchable Synthesis of Spirooxindole-Chromeno[2,3-b]Indoles and SpirooxindoleChromeno[3,2-b]Indoles. J. Org. Chem. 2020, 85 (5), 3638-3654. https://doi.org/10.1021/acs.joc.9b03300.

(12) Nandi, R. K.; Perez-Luna, A.; Gori, D.; Beaud, R.; Guillot, R.; Kouklovsky, C.; Gandon, V.; Vincent, G. Triflic Acid as an Efficient Brønsted Acid Promoter for the Umpolung of N-Ac Indoles in Hydroarylation Reactions. Adv. Synth. Catal. 2018, 360 (1), 161-172. h(a) ttps://doi.org/10.1002/adsc.201701074.

(13) For reviews on spiroindoline derivatives: (a) Bariwal, J.; Voskressensky, L. G.; Eycken, E. V. V. der. Recent Advances in Spirocyclization of Indole Derivatives. Chem. Soc. Rev. 2018, 47, 3831-3848. https://doi.org/10.1039/C7CS00508C; (b) James, M. J.; O’Brien, P.; Taylor, R. J. K.; Unsworth, W. P. Synthesis of Spirocyclic Indolenines. Chem. - Eur. J. 2016, 22, 2856-2881. https://doi.org/10.1002/chem.201503835; (c) Boddy, A. J.; Bull, J. A. Stereoselective Synthesis and Applications of Spirocyclic Oxindoles. Org. Chem. Front. 2021, 8, $1026-1084$. https://doi.org/10.1039/D0QO01085E.

(14) (a) Magné, V.; Sanogo, Y.; Demmer, C. S.; Retailleau, P.; Marinetti, A.; Guinchard, X.; Voituriez, A. Chiral Phosphathiahelicenes: Improved Synthetic Approach and Uses in Enantioselective Gold(I)-Catalyzed [2 + 2] Cycloadditions of N-Homoallenyl Tryptamines. ACS Catal. 2020, 10 (15), 8141-8148. https://doi.org/10.1021/acscatal.0c01819; (b) Sabat, N.; Soualmia, F.; Retailleau, P.; Bendjdia, A.; Berteau, O.; Guinchard, X. Gold-Catalyzed Spirocyclization Reactions of N-Propargyl Tryptamines and Tryptophans in Aqueous Media. Org. Lett. 2020, 22, 4344 - 4349. https://doi.org/10.1021/acs.orglett.0c01370; (c) Magné, V.; Retailleau, P.; Marinetti, A.; Voituriez, A.; Guinchard, X. GoldCatalyzed Synthesis of 2-Sulfenylspiroindolenines via Spirocyclizations. Molbank 2018, 2018 (1), M985. https://doi.org/10.3390/M985; (d) Glinsky-Olivier, N.; Retailleau, P.; Guinchard, X. Gold-Catalyzed Synthesis of Spirofused Indoloquinuclidines. Eur. J. Org. Chem. 2018, 2018 (42), 5823-5829. https://doi.org/10.1002/ejoc.201800357; (e) Magné, V.; Marinetti, A.; Gandon, V.; Voituriez, A.; Guinchard, X. Synthesis of Spiroindolenines via Regioselective Gold(I)-Catalyzed Cyclizations of N-Propargyl Tryptamines. Adv. Synth. Catal. 2017, 359 (22), 4036-4042. https://doi.org/10.1002/adsc.201700932; (f) Magné, V.; Blanchard, F.; Marinetti, A.; Voituriez, A.; Guinchard, X. Synthesis of Spiro[Piperidine-3,3'-Oxindoles] via Gold(I)-Catalyzed Dearomatization of N-Propargyl- and N-Homoallenyl-2-Bromotryptamines. Adv. Synth. Catal. 2016, 358 (21), 3355-3361. https://doi.org/10.1002/adsc.201600398; for a review on Au(I)-catalyzed indole functionnalization, including dearomatization strategies, see: (g) Milcendeau, P.; Sabat, N.; Ferry, A.; Guinchard, X. Gold-Catalyzed Enantioselective Functionalization of Indoles. Org. Biomol. Chem. 2020, 18 (31), 6006-6017. https://doi.org/10.1039/D0OB01245A.

(15) With 2.5 equiv. of TfOH in $\mathrm{CH}_{2} \mathrm{Cl}_{2}$, the reaction is considerably slower but could indeed deliver $22 \%$ of $\mathbf{1 5 q}$ after $48 \mathrm{~h}$ (after $3.5 \mathrm{~h}$ only dimer $\mathbf{4 q}$ was obtained in $43 \%$ yield along with recovered skatole 1q). Interestingly after 48 h, $59 \%$ of $\mathbf{1 5 q}$ were obtained with 2.5 equiv. of TfOH in HFIP (only traces after $3.5 \mathrm{~h}$ ).

(16) (a) Hinman, R. L.; Whipple, E. B. The Protonation of Indoles: Position of Protonation. J. Am. Chem. Soc. 1962, 84 (13), $2534-2539$. https://doi.org/10.1021/ja00872a017; (b) Hinman, R. L.; Lang, J. The Protonation of Indoles. Basicity Studies. The Dependence of Acidity Functions on Indicator Structure. J. Am. Chem. Soc. 1964, 86 (18), 3796-3806. https://doi.org/10.1021/ja01072a040; (c) Remers, W. A. Properties and Reactions of Indoles, Isoindoles, and Their Hydrogenated Derivatives. In Chemistry of Heterocyclic Compounds; John Wiley \& Sons, Ltd, 1971; pp 1-226. https://doi.org/10.1002/9780470186923.ch1.

(17) (a) Koizumi, M.; Komaki, Y.; Titani, T. Über Den Austausch Der Wasserstoffatome Zwischen Pyrrol, Indol, Sowie Ihren Methylderivaten Und Wasser. V. Austausch Der Wasserstoffatome Zwischen N-Methylindol Und Wasser. Bull. Chem. Soc. Jpn. 1938, 13 (10), 643-651. https://doi.org/10.1246/bcsj.13.643; (b) Koizumi, M. Über Den Austausch Der Wasserstoffatome Zwischen Pyrrol, Indol Sowie Ihren Methylderivaten Und Wasser. VI. Austausch Der Wasserstoffatome Zwischen $\alpha$-Methyl-, $\beta$-Methyl- Sowie $\alpha, \beta$-Dimethylindol Und Wasser. Bull. Chem. Soc. Jpn. 1939, 14 (10), 453-461. https://doi.org/10.1246/bcsj.14.453.

(18) Noland, W. E.; Robinson, D. N. Electrophilic Substitution in Skatole and Its Derivatives. Tetrahedron 1958, 3 (1), 68-72. https://doi.org/10.1016/S0040-4020(01)82612-0.

(19) (a) Glinsky-Olivier, N.; Yang, S.; Retailleau, P.; Gandon, V.; Guinchard, X. Enantioselective Gold-Catalyzed Pictet-Spengler Reaction. Org. Lett. 2019, 21 (23), 9446-9451. https://doi.org/10.1021/acs.orglett.9b03656; (b) Milcendeau, P.; Zhang, Z.; Glinsky-Olivier, N.; van Elslande, E.; Guinchard, X. Au(I)-Catalyzed Pictet-Spengler Reactions All around the Indole Ring. J. Org. Chem. 2021, 86 (9), 6406-6422. https://doi.org/10.1021/acs.joc.1c00270.

(20) See for instance: (a) Zheng, C.; Xia, Z.-L.; You, S.-L. Unified Mechanistic Understandings of Pictet-Spengler Reactions. Chem 2018, 4 (8), 1952-1966. https://doi.org/10.1016/j.chempr.2018.06.006; (b) Gobé, V.; Gandon, V.; Guinchard, X. Reactions Involving Tryptamines and $\delta$-Allenyl Aldehydes: Competition between Pictet-Spengler Reaction and Cyclization to 1-Aminotetralins. Adv. Synth. Catal. 2018, 360 (6), 1280-1288. https://doi.org/10.1002/adsc.201701487; (c) Liddon, J. T. R.; Rossi-Ashton, J. A.; Clarke, A. K.; Lynam, J. M.; Taylor, R. J. K.; Unsworth, W. P. Divergent Reactivity of Indole-Tethered Ynones with Silver(I) and Gold(I) Catalysts: A Combined Synthetic and Computational Study. Synthesis 2018, 50 (24), 4829-4836. https://doi.org/10.1055/s-0037-1610181.

(21) Treatment of dimer $\mathbf{4 a}$ with an excess of triflic acid led to the formation of 3,3-spiroindoline $\mathbf{1 5 a}$.

(22) (a) Pozhydaiev, V.; Power, M.; Gandon, V.; Moran, J.; Lebœuf, D. Exploiting Hexafluoroisopropanol (HFIP) in Lewis and Brønsted AcidCatalyzed Reactions. Chem. Commun. 2020, 56 (78), 11548-11564. https://doi.org/10.1039/D0CC05194B; DFT-computed Lewis acid-HFIP clusters: (b) Qi, C.; Gandon, V.; Lebœuf, D. Calcium(II)-Catalyzed Intermolecular Hydroarylation of Deactivated Styrenes in Hexafluoroisopropanol. Angew. Chem. Int. Ed. 2018, 57 (43), 14245-14249. https://doi.org/10.1002/anie.201809470. (c) Qi, C.; Hasenmaile, F.; Gandon, V.; Lebœuf, D. Calcium(II)-Catalyzed Intra- and Intermolecular Hydroamidation of Unactivated Alkenes in Hexafluoroisopropanol. ACS Catal. 2018, 8 (3), 1734-1739. https://doi.org/10.1021/acscatal.7b04271; DFT computed TfOH-HFIP clusters: (d) Zhou, Y.; Xue, R.-C.; Feng, Y.; Zhang, L. How Does HOTf/HFIP Cooperative System Catalyze the Ring-Opening Reaction of Cyclopropanes? A DFT Study. Asian J. Org. Chem. 2020, 9 (2), 311-316. https://doi.org/10.1002/ajoc.202000031. (e) Zhang, S.; Vayer, M.; Noël, F.; Vuković, V. D.; Golushko, A.; Rezajooei, N.; Rowley, C. N.; Lebœuf, D.; Moran, J. Unlocking the Friedel-Crafts Arylation of Primary Aliphatic Alcohols and Epoxides Driven by Hexafluoroisopropanol. Chem 2021, 7 (12), 3425-3441. https://doi.org/10.1016/j.chempr.2021.10.023.

(23) Yao, J.; Li, C.-L.; Fan, X.; Wang, Z.; Yu, Z.-X.; Zhao, J. Ynamide Protonation-Initiated Cis-Selective Polyene Cyclization and Reaction Mechanism. CCS Chem. 2021. https://doi.org/10.31635/ccschem.021.202101331.

(24) (a) Olah, G. A.; Klumpp, D. A. Superelectrophiles and Their Chemistry; John Wiley \& Sons, Inc., 2007; (b) Olah, G. A.; Prakash, G. K. S.; Molnár, Á.; Sommer, J. Carbocations in Superacid Systems. In Superacid Chemistry; John Wiley \& Sons, Ltd, 2009; pp 83-310. https://doi.org/10.1002/9780470421604.ch3; for selected examples: (c) Naredla, R. R.; Zheng, C.; Nilsson Lill, S. O.; Klumpp, D. A. Charge Delocalization and Enhanced Acidity in Tricationic Superelectrophiles. J. Am. Chem. Soc. 2011, 133 (33), 13169-13175. https://doi.org/10.1021/ja2046364; (d) Gurskaya, L. Y.; Belyanskaya, D. S.; Ryabukhin, D. S.; Nilov, D. I.; Boyarskaya, I. A.; Vasilyev, A. V. Reactions of N,3-Diarylpropiolamides with Arenes under Superelectrophilic Activation: Synthesis of 4,4-Diaryl-3,4-Dihydroquinolin2(1H)-Ones and Their Derivatives. Beilstein J. Org. Chem. 2016, 12 (1), 950-956. https://doi.org/10.3762/bjoc.12.93; (e) Beaud, R.; Michelet, 
B.; Reviriot, Y.; Martin-Mingot, A.; Rodriguez, J.; Bonne, D.; Thibaudeau, S. Enantioenriched Methylene-Bridged Benzazocanes Synthesis by Organocatalytic and Superacid Activations. Angew. Chem. Int. Ed. 2020, 59 (3), 1279-1285. https://doi.org/10.1002/anie.201912043.

(25) For compound 1a leading to 6-membered ring spiroindoline 15a, the pathway via a 1,3-dication such as 21 involving two molecules of triflic acid (one to protonate the indolic nitrogen and one to protonate the C2-position) has an activation barrier of $45 \mathrm{kcal} / \mathrm{mol} \mathrm{which} \mathrm{compares} \mathrm{very}$ unfavorably to the $\mathrm{C} 3$-monocation pathway with a $(\mathrm{TfOH})_{2}$ cluster described in Figure 1. 